\title{
Characterization of crop vitality and resource use efficiency by means of combining imaging spectroscopy based plant traits
}

\section{Conference Paper}

Author(s):

Liebisch, Frank; Küng, Gabriela; Damm, Alexander; Walter, Achim

Publication date:

2014

Permanent link:

https://doi.org/10.3929/ethz-a-010782109

Rights / license:

In Copyright - Non-Commercial Use Permitted

Originally published in:

https://doi.org/10.1109/WHISPERS.2014.8077612 


\title{
CHARACTERIZATION OF CROP VITALITY AND RESOURCE USE EFFICIENCY BY MEANS OF COMBINING IMAGING SPECTROSCOPY BASED PLANT TRAITS
}

\author{
Frank Liebisch (1), Gabriela Küng (1), Alexander Damm (2) \& Achim Walter (1)
}

(1) Institute of Agricultural Sciences, Group of Crop Science, ETH Zürich, Universitätsstrasse 2, 8092, Zürich, Switzerland

(2) Remote Sensing Laboratories, University of Zürich, Winterthurerstrasse 190, 8057 Zürich, Switzerland

\begin{abstract}
In this contribution measurements of the Airborne Prism Experiment (APEX) imaging spectrometer were used to derive products related to plant traits, e.g., leaf chlorophyll, carotenoid, anthocyanin, and water content, leaf greenness, biomass, and leaf area index. The Apex products were highly correlated to the related ground truth measurements in major crops under experimental and field situations. The relationship of APEX derived NDVI (NDVI $\left.{ }_{\mathrm{APEX}}\right)$ with ground measured NDVI and canopy cover is shown in detail. Additionally, interrelations between the aerial detected traits are discussed. The combination of the presented remotely measured plant traits can potentially give crop specific indications of their growth status and vitality. Such tools could help to improve resource use efficiency in agricultural systems and are needed for applications in precision agriculture and mapping of land use and land cover for scientific purposes or decision making.
\end{abstract}

Index Terms - APEX, major crops, precision agriculture, crop performance, crop vitality

\section{INTRODUCTION}

The worlds food demand is estimated to increase by about $60 \%$ until 2050 [1]. To meet that demand, agriculture needs to increase production and resource use efficiency. Remote sensing approaches, in particular imaging spectroscopy, are currently used to detect land use and cover, and status and functional changes of ecosystems vegetation caused by seasonality and by environmental changes such as drought spells. Additionally, low distance sensing methods are applied in agriculture or breeding research to identify crop genotypes adapted to certain environmental conditions $[2,3]$. The remote detection and performance evaluation of major crops are important tools for precision agriculture, agricultural research and decision makers.

Crop performance is mainly affected by environmental conditions such as water and nutrient availability, temperature during the growing season, soil conditions and crop management. However, the habitus of the crop plant and thus its optical properties measurable with remote sensing instruments are also affected by growth stage (phenology), crop species and genotype. To identify crop status and vitality with remote sensed indicators it is important to know the range of investigated crop parameters under optimal and sub optimal conditions.

Crop performance at the end of the season can be measured as biomass or yield of grains or other harvesting products. During the growing season crop vitality is often characterized by traits such as growth, leaf greenness, leaf area index (LAI), canopy cover (CC), leaf water content (LWC) and leaf chlorophyll content. Many of such traits can be remotely sensed by means of spectral indices. Leaf greenness and plant biomass is often estimated using the normalized difference vegetation index (NDVI) [4]. Other indices used as proxies for plant traits are the MCARI2 for LAI [5], the normalized difference water index (NDWI) for leaf water content [6] and pigment contents such as chlorophyll (CHL), carotenoids (CAR) and anthocyanin (ANTH) [7-9].

However, many of the remote detected information might be highly correlated because measurement principles, such as used spectral channels overlap or exploit similar spectral regions. Such traits might be biomass, leaf greenness and CHL. Other parameters might be difficult to measure during certain phases of plant development when canopy cover is low and thus the soil influence in the signal is high or when chlorophyll contents are high and might mask the absorption information of anthocyanin [10].

To reliably identify crops and their current performance a combination of different traits may be needed. Such integrative approaches might allow the indication of the source of the limiting factor, such as drought stress or nutrient deficiency in some cases. Such information on large scales is important to improve resource use efficiency in agricultural systems.

Under drought conditions, for example LAI, CC and LWC are likely to be reduced, whereas NDVI and CHL are only marginally affected. Under Nitrogen deficiency reduced NDVI, CC and CHL are reduced, but not LWC.

This study aims to show examples for APEX biosphere products and their validation for crop traits. Secondly, to present variation found in the APEX products measured in corn fields in the region of Eschikon, Switzerland and to 
discuss a first attempt to identify causes for sub optimal growth.

\section{METHODS AND DATA COLLECTION}

\subsection{Investigated locations and crops}

For the present study a long term fertilizer experiment and the agricultural area surrounding the ETH research station in Eschikon were used for investigations. The long term fertilizer experiment was located at the Agroscope research station in Reckenholz $\left(47^{\circ} 25^{\prime} 31.28^{\prime \prime} \mathrm{N}\right.$, $\left.8^{\circ} 31^{\prime} 0.11^{\prime \prime E}\right)$. The fertilizer trial was started in 1987 and consisted of eight different input treatments: no fertilization, mineral NPK, minus $\mathrm{N}$, minus $\mathrm{P}$, minus $\mathrm{K}$, manure, manure plus lime, slurry [11]. In 2013 the seven crops corn, sugar beet, spring wheat, annual and biannual temporal grassland, winter barley and potato were cultivated. The plot size was approximately $4 \times 8 \mathrm{~m}$ with one $\mathrm{m}$ transition between plots.

The investigated agricultural fields were located in the vicinity of the agricultural research station of the ETH Zürich $\left(47^{\circ} 44^{\prime} 92.13^{\prime \prime} \mathrm{N}, \quad 8^{\circ} 68^{\prime} 22.38^{\prime} \mathrm{E}\right)$. They were managed by the agricultural school (Strickhof Lindau) or local farmers according to best management practices. Field validation plots comprised the crops: corn, sugar beet, winter wheat, oil seed rape, biannual temporal grassland, spring barley, soy bean and potato.

The location of experimental and field plots used for validation were determined by GPS. The present field crops in the Eschikon area were mapped on the 31.08.2013. A total of 22 corn fields were identified.

\subsection{Ground truth measurements}

Crop development stage was determined using the $\mathrm{BBCH}$ scale [12]. $\mathrm{NDVI}_{\text {ground }}$ and canopy cover (CC) were measured with a two-channel, 12.2 megapixel CMOS vegetative stress camera (Canon EOS 450D NDVI, modified by LDP LLD, Carlsted, USA, www.maxmax.com). LAI was detected with a LAI-2000 plant canopy analyzer (Li-Cor, Inc., Lincoln, NE). SPAD meter measurements were done on ten adjacent plants using a SPAD meter (Konica Minolta Sensing Inc., Osaka, Japan). Plant sampling for biomass, dry matter, LWC and determination of chlorophyll content were done on one selected row in the middle of a measurement plot. Chlorophyll content was analyzed separately on the youngest fully developed leaves.

\subsection{APEX}

Imaging spectroscopy data was collected on the 06.07.2013 in Reckenholz and 30.08.2013 in Eschikon using the imaging spectrometer APEX (Airborne Prism
Experiment). For more details on data processing see [13, 14]. Five APEX products, i.e., NDVI [4], MCARI2 and LAI [5], CHL [8], NDWI [6], were calculated.

APEX product data of the validation locations and corn fields was extracted using ENVI 5.1 (EXELIS). The Pearson product moment correlation was calculated using $\mathrm{R}$ version $3.02[15]$.

\section{RESULTS AND DISCUSSION}

The $\mathrm{NDVI}_{\text {Apex }}$ was highly correlated to plant and plot $\mathrm{NDVI}_{\text {ground }}$ (Fig. 1A). The data obtained in the long term fertilizer trial indicate that the observed relationships are applicable for the major crops in general but slight differences between the crops were observed. For example sugar beet showed lower $\mathrm{NDVI}_{\text {ground }}$ correlated to $\mathrm{NDVI}_{\mathrm{APEX}}$ with a similar slope (Fig. 1A).

Because APEX pixels were approximately $2 \times 2 \mathrm{~m}$ of size on ground the $\mathrm{NDVI}_{\mathrm{APEX}}$ reflects mixed information about plant $\mathrm{NDVI}_{\text {ground }}$ and $\mathrm{CC}$ (Fig. 1B). For the validation plots in Eschikon similar relationships were observed (Tab. 1) but data showed less variation than in the fertilizer trial. $\mathrm{LAI}_{\mathrm{APEX}}$ and MCARI2 were significantly correlated to $\mathrm{LAI}_{\text {ground }}$ in experimental $(0.79 * * *)$ and in the field plots (Tab. 1).
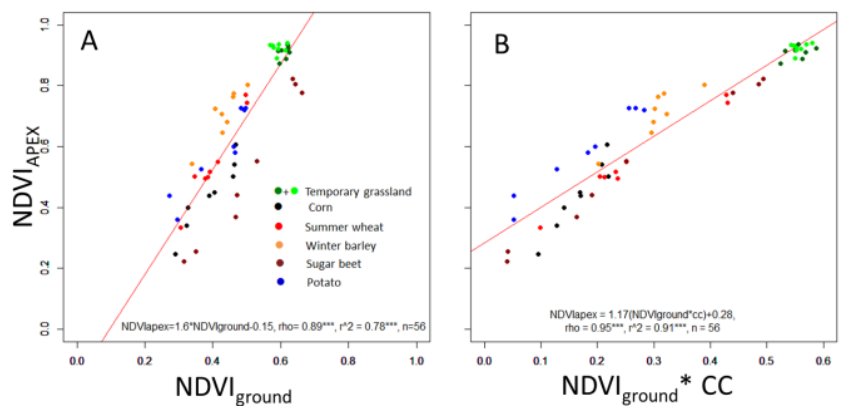

Figure 1: Correlation of $\mathrm{NDVI}_{\mathrm{APEX}}$ with $\mathrm{NDVI}_{\text {ground }}(\mathrm{A})$ and the product between $\mathrm{NDVI}_{\text {ground }}$ and $\mathrm{CC}(\mathrm{B})$ determined in a long term fertilizer trial.

Plant dry matter was correlated to $\mathrm{NDVI}_{\mathrm{APEX}}$, NDWI and MCARI2 reflecting a close relationship between those indices. LWC was well correlated to NDWI but to no other APEX products (Tab. 1). The NDWI on the other hand was also correlated to growth stage, dry matter and chlorophyll content. CHL was correlated to SPAD measurements and chlorophyll content but also to $\mathrm{NDVI}_{\text {ground }}, \mathrm{CC}$ and $\mathrm{LAI}_{\text {ground }}$ (Tab. 1). These interrelationships indicate effects caused by other canopy properties then chlorophyll content and thus CHL should be interpreted with care.

The six APEX products extracted from 22 corn fields (Fig. 2) show the variation that can be found in the field. In 
that area local climate and weather was similar and differences in crop traits mainly originate from differences in soil properties and management practices.

Table 1: Correlation between APEX plant trait products to ground measured plant traits as measured in Eschikon including the major crops. Stars indicate the significance level $\mathrm{p}<0.05 *, 0.01 * *$ and $0.001 * * *$.

\begin{tabular}{|c|c|c|c|c|c|}
\hline \multirow[b]{2}{*}{ Ground parameter } & \multicolumn{5}{|c|}{ Apex products } \\
\hline & NDWI & NDVI & MCARI2 & LAI & CHL \\
\hline BBCH & $\begin{array}{l}-0.64 \\
* * *\end{array}$ & $\begin{array}{l}0.49 \\
* * *\end{array}$ & $\begin{array}{l}0.71 \\
* * *\end{array}$ & $\begin{array}{l}0.62 \\
* * *\end{array}$ & $\begin{array}{l}-0.1 \\
\text { ns }\end{array}$ \\
\hline $\begin{array}{l}\text { Dry matter } \\
(\mathrm{g} / \mathrm{m} 2)\end{array}$ & $\begin{array}{l}-0.45 \\
* * *\end{array}$ & $\begin{array}{l}0.4 \\
* * *\end{array}$ & $\begin{array}{l}0.5 \\
* * *\end{array}$ & $\begin{array}{l}0.25 \\
*\end{array}$ & $\begin{array}{l}-0.12 \\
\text { ns }\end{array}$ \\
\hline $\begin{array}{l}\text { Water content } \\
(\mathrm{cm} / \mathrm{m} 2)\end{array}$ & $\begin{array}{l}-0.36 \\
* *\end{array}$ & $\begin{array}{l}-0.07 \\
\text { ns }\end{array}$ & $\begin{array}{l}-0.16 \\
\text { ns }\end{array}$ & $\begin{array}{l}-0.15 \\
\text { ns }\end{array}$ & $\begin{array}{l}-0.18 \\
\text { ns }\end{array}$ \\
\hline $\begin{array}{l}\text { NDVI Iround (plant + } \\
\text { soil) }\end{array}$ & $\begin{array}{l}-0.18 \\
\mathrm{~ns}\end{array}$ & $\begin{array}{l}0.72 \\
* * *\end{array}$ & $\begin{array}{l}0.88 \\
* * *\end{array}$ & $\begin{array}{l}0.77 \\
* * *\end{array}$ & $\begin{array}{l}0.41 \\
* * *\end{array}$ \\
\hline Canopy cover (\%) & $\begin{array}{l}-0.09 \\
\text { ns }\end{array}$ & $\begin{array}{l}0.73 \\
* * *\end{array}$ & $\begin{array}{l}0.89 \\
* * *\end{array}$ & $\begin{array}{l}0.79 \\
* * *\end{array}$ & $\begin{array}{l}0.31 \\
* *\end{array}$ \\
\hline $\mathbf{N D V I}_{\text {ground }}$ (plant) & $-0.1 \mathrm{~ns}$ & $\begin{array}{l}0.42 \\
* * *\end{array}$ & $\begin{array}{l}0.45 \\
* * *\end{array}$ & $\begin{array}{l}0.55 \\
* * *\end{array}$ & $\begin{array}{l}0.47 \\
* * *\end{array}$ \\
\hline $\begin{array}{l}\mathbf{L A} \mathbf{I}_{\text {ground }} \\
(\mathrm{m} 2 / \mathrm{m} 2)\end{array}$ & $\begin{array}{l}-0.02 \\
\mathrm{~ns}\end{array}$ & $\begin{array}{l}0.6 \\
* * *\end{array}$ & $\begin{array}{l}0.75 \\
* * *\end{array}$ & $\begin{array}{l}0.89 \\
* * *\end{array}$ & $\begin{array}{l}0.33 \\
*\end{array}$ \\
\hline SPAD & $\begin{array}{l}0.32 \\
\mathrm{~ns}\end{array}$ & $\begin{array}{l}0.54 \\
* *\end{array}$ & $\begin{array}{l}0.41 \\
*\end{array}$ & $\begin{array}{l}0.26 \\
\text { ns }\end{array}$ & $\begin{array}{l}0.59 \\
*\end{array}$ \\
\hline $\begin{array}{l}\text { Chlorophyll } \\
\text { content }(\mu \mathrm{g} / \mathrm{cm} 2)\end{array}$ & $\begin{array}{l}-0.65 \\
* *\end{array}$ & $\begin{array}{l}-0.56 \\
* *\end{array}$ & $\begin{array}{l}-0.57 \\
* *\end{array}$ & $\begin{array}{l}-0.53 \\
* *\end{array}$ & $\begin{array}{l}-0.53 \\
*\end{array}$ \\
\hline
\end{tabular}

The pigment products ranged from 1 to $11,0.1$ to 1.2 and -0.22 to $0.24 \mu \mathrm{g} / \mathrm{cm}^{2}$ for CHL, CAR and ANTH (Fig. 2). The observations for CHL and CAR were in an expectable range. The negative values found for ANTH may indicate that anthocyanin levels were below the detection limit or the need for methodological adjustments. However, the significant negative correlations found between $\mathrm{CHL}$ and CAR and ANTH $(-0.66 * * *$ and $-0.67 * * *)$, indicate an interaction between high CHL and low CAR and ANTH.

The NDWI ranged from below zero to 0.3 with the highest values observed in fields with highest $\mathrm{NDVI}_{\mathrm{APEX}}$ and $\mathrm{LAI}_{\mathrm{APEX}}$ indicating high standing biomass or low fraction of soil in the measured field. That relationship is confirmed by the high positive correlation of NDWI to $\mathrm{NDVI}_{\mathrm{APEX}}(0.86 * * *)$ and $\mathrm{LAI}_{\mathrm{APEX}}(0.91 * * *)$. The positive interaction prevents a clear interpretation of NDWI for leaf water content as it is known to be affected by amount of standing biomass or fraction of soil cover [6].

Knowing actual canopy cover for example could improve reliability of the interpretation of remote detected NDWI. Such information could be potentially derived from the relationship of $\mathrm{CC}$ to $\mathrm{NDVI}_{\mathrm{APEX}}$ as shown in Fig. 1B.

A test calculation revealed that field 23 was significantly reduced in average canopy cover 0.79 as compared to the other fields which ranged from 0.9 to 1.0 .
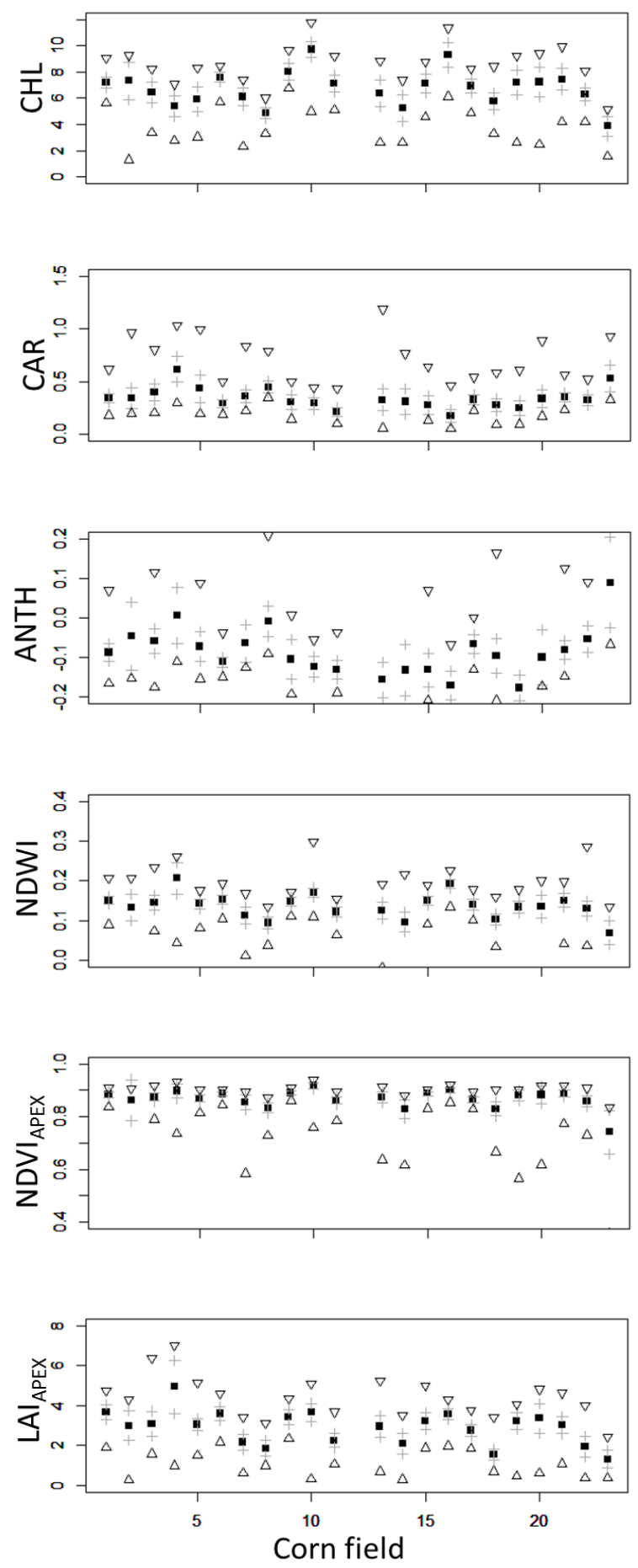

Figure 2: Variance of the APEX products: LAI, NDVI, NDWI, CHL, CAR and ANTH in 22 corn fields as shown by mean $(\boldsymbol{\square})$, standard deviation $(+)$, minimum $(\triangle)$ and $\operatorname{maximum}(\nabla)$. 
Combining trait information may potentially be used to identify sources for plant growth limitation. Whereas we can identify high and low values for each remote detected traits (Fig. 2) some contrasting combinations were found. In field four for example we found relatively high values for all traits but CHL. That observation is interesting because generally high chlorophyll concentrations are linked to high NDVI and LAI observations. Additionally, high contents of CAR and ANTH were indicated. Such a combination might indicate a shift in plant $\mathrm{N}$ status caused by $\mathrm{N}$ deficiency or beginning senescence not yet affecting biomass or CC. In field 10 we observed all traits to be relatively high except CAR and ANTH. Such a combination could indicate a well grown corn stand. In contrast field 23 showed low CHL, NDWI, NDVI ${ }_{\mathrm{APEX}}$, and $\mathrm{LAI}_{\mathrm{APEX}}$ and relative high values for $\mathrm{CAR}$ and ANTH. From the previous sections it is clear that the low indications might be caused by the low canopy cover, which might be caused by stress during earlier growth stages. The low CHL and high ANTH might be indicative for previous stress experience such as drought (observed in that field in July) or nitrogen deficiency or both.

The inclusion of several spectral indicators representing a wide range of plant traits such as leaf $\mathrm{N}$ concentration [16] potentially increase reliability and power of multi trait indication by imaging spectroscopy techniques.

\section{CONCLUSION}

This contribution shows some examples for successful validation of APEX products for important plant traits such as leaf chlorophyll, carotenoid, anthocyanin and water content, leaf greenness, biomass and LAI in major crops in experimental and in field situations. Such validation is important information to use these remote sensing products for applications in precision agriculture and mapping of land use and land cover for scientific purposes and decision making. The combination of the presented remote detected traits can potentially give crop specific indications of their growth status and vitality. Such tools could help to improve resource use efficiency in agricultural systems.

\section{ACKNOWLEDGEMENTS}

This Work was supported by a grant of the Swiss University Conference and the ETH-Board in the frame of the Swiss Earth Observatory Network (SEON). We thank the APEX team, H. Zellweger and N. Kirchgessner for their precious help for this project.

\section{REFERENCES}

[1] FAO, "WORLD AGRICULTURE TOWARDS

2030/2050. The 2012 Revision," 2012.
[2] M. Jansen, F. Pinto, K. A. Nagel et al., "Non-invasive Phenotyping Methodologies Enable the Accurate Characterization of Growth and Performance of Shoots and Roots," Genomics of Plant Genetic Resources, R. Tuberosa et al., ed., Dordrecht: Springer Science+Business Media, 2014.

[3] A. Walter, B. Studer, and R. Kölliker, "Advanced phenotyping offers opportunities for improved breeding of forage and turf species," Annals of Botany, 2012.

[4] N. Pettorelli, The Normalized Difference Vegetation Index, pp. 208, Oxford: OUP, 2013.

[5] D. Haboudane, J. R. Miller, E. Pattey et al., "Hyperspectral vegetation indices and novel algorithms for predicting green LAI of crop canopies: Modeling and validation in the context of precision agriculture," Remote Sensing of Environment, vol. 90, no. 3, pp. 337-352, 2004.

[6] B.-C. Gao, "NDWI - A normalized difference water index for remote sensing of vegetation liquid water from space," Remote Sensing of Environment, vol. 58, no. 3, pp. 257-266, 1996.

[7] D. Haboudane, N. Tremblay, J. R. Miller et al., "Remote estimation of crop chlorophyll content using spectral indices derived from hyperspectral data," IEEE Transactions on Geoscience and Remote Sensing, vol. 46, no. 2, pp. 423-437, 2008. [8] A. A. Gitelson, G. P. Keydan, and M. N. Merzlyak, "Three-band model for noninvasive estimation of chlorophyll, carotenoids, and anthocyanin contents in higher plant leaves," Geophysical Research Letters, no. 33, 2006.

[9] S. L. Ustin, A. A. Gitelson, S. Jacquemoud et al., "Retrieval of foliar information about plant pigment systems from high resolution spectroscopy," Remote Sensing of Environment, vol. 113, Supplement 1, pp. 67-77, 2009.

[10] H. G. Jones, and R. A. Vaughan, Remote sensing of vegetation, principles, techniques and applications, Oxford: Oxford University Press, 2010.

[11] R. M. Hausherr, E. Brack, and R. Flisch, "Auswirkungen suboptimaler Düngung auf Ackerkulturen," AGRARForschung, vol. 14, no. 9, pp. 400-405, 2007.

[12] BBLF, "Entwicklungsstadien mono- und dikotyler Pflanzen. Biologische Bundesanstalt für Land und

Forstwirtschaft," BBCH Monografie, 2001.

[13] P. D’Odorico, L. Guanter, M. E. Schaepman et al., "Performance assessment of onboard and scene-based methods for Airborne Prism Experiment spectral characterization," Applied Optics, vol. 50, no. 24, pp. 4755-4764, 2011.

[14] A. Hueni, S. Sterckx, M. Jehle et al., "Operational status of APEX and characteristics of the APEX open science data set," Geoscience and Remote Sensing Symposium (IGARSS), IEEE International, pp. 5009 - 5012, 2012.

[15] R-Development-Core-Team, "R: A language and environment for statistical computing," R Foundation for Statistical Computing, Vienna, Austria. ISBN 3-900051-07-0, URL http://www.R-project.org., 2008].

[16] P. F. Chen, D. Haboudane, N. Tremblay et al., "New spectral indicator assessing the efficiency of crop nitrogen treatment in corn and wheat," Remote Sensing of Environment, vol. 114, no. 9, pp. 1987-1997, 2010. 